\title{
Retail Managers: Laissez-Faire Leadership Is Synonymous with Unsuccessful Conflict Management Styles
}

\author{
Etta C. Gray ${ }^{1}$, James Arthur Williams ${ }^{2}$ \\ ${ }^{1}$ University of Phoenix, Phoenix, USA \\ ${ }^{2}$ James Madison University, Harrisonburg, USA \\ Email: ettamaye2@email.phoenix.edu, will22ja@jmu.edu \\ Received July $9^{\text {th }}$, 2012; revised August $12^{\text {th }}$, 2012; accepted August 21 ${ }^{\text {st }}, 2012$
}

\begin{abstract}
Retail managers were examined to determine their leadership styles and any potential correlations to conflict management styles. Research findings suggest that successful retail managers exhibit transformational leadership styles, and those that exhibit laissez-faire leadership is strongly correlated with avoidance conflict management style. The Conflict Management Style (CMS) and Multi Leadership Questionnaire (MLQ) instruments were used to survey participants in this study. A MLQ scoring manual was used to identify leadership styles, and a CMS scoring manual was used to determine conflict management styles. Pearson correlation (SPSS, version 17.0) was used to correlate between MLQ and CMS findings.
\end{abstract}

Keywords: Transformational Leadership; Conflict Management; Retail Managers; MLQ; Avoidance Conflict Management

\section{Introduction}

Conflict has a profound effect on leaders attempting to lead within complex and convoluted work environments, but successful leaders embrace conflict to create inspirational leadership styles in these challenging situations (Runde \& Flanagan, 2008). Some conflicts that might occur in the retail work environment can stem from opposing management perspectives, turnover, and fractured work relationships. Leaders in the retail industry may change the conflict culture of their organizations through recognizing behavioral patterns of employees. According to Runde and Flanagan (2008), managers can change conflict culture by aligning constructive conflict responses to the organization's vision, policies, and performance measures. Effective leadership styles are essential to the success of intricate organizations (Latham \& Vinyard, 2004).

Improperly or poorly, managing conflicts in retail work environments can create financial losses that impede the progression of productive retail entities (Kanchier, 2005). According to Katz (2006), unresolved conflict has become an unrecognizing cost factor in many organizations. Multiple conflicts shift the strategic planning from production and employee performance to combating potential contingencies among internal relationships (Sherman, 2009). Korkmaz (2007) indicated that managers could resolve internal conflict when those managers understood the concerns of their employees. An examination of leadership styles and how to resolve conflict in small retail businesses is pertinent to improving work environments because leaders must know when and how to take action (Danley, 2006). Managing conflict is an opportunity for organizations to expand the contextual aspects of conflict while decreasing the consequences (Bruk-Lee, 2007).

Conflict is characterized as a difference among two or more individuals, involving no bonding to create tension, disagreement, emotion, or polarization (Korkmaz, 2007). Assessing numerous research studies pertaining to managing conflict, there are a few research studies that focus on correlation between leadership styles and conflict management styles in the retail environment. This research study aims to investigate retail managers' effective leadership styles and any correlations to effectual conflict management styles. The results can present patterns of leadership behaviors needed to combat present and future issues that might impede the progression of complex retail work environments.

\section{Literature Review}

Leadership is essential to the development and maturation of diversified workforce populations (Latham \& Vinyard, 2004). Effective leadership is in demand for retail organizations in a competitive, fast-moving environment (Sheard \& Kakabadse, 2002). To be effective, leaders must display consistent core beliefs and behaviors; yet at the same time simultaneously adopt his or her style to mesh with the culture of their organization (Sheard \& Kakabadse, 2002). Effective leadership is used to manage organization's goals and objectives (Tubbs \& Schulz, 2006). Successful leaders used a transformational leadership style to motivate and inspire constituents to align their behaviors and actions to accomplish organizational goals and objectives (Ackoff, 1999).

Transformational leadership sets the standard level of human interaction between the leader and follower. This can be accomplished by the relationship the leader develops with followers wanting to exceed to the next level; therefore creating a new era of leaders (Banerji \& Krishnan, 2000). Transformational leadership is the ability of a leader to build trust, loyalty, and admiration in followers, and express his or her individual interests to the entire group (Eagly, Johannesen-Schmidt, \& Van Engen, 2003). Managing conflict may come easy to transformational leaders, the leadership style is a behavior process comprised charisma, intellectual stimulation, and individualized consideration (Bass \& Avolio, 2004). Conflict not effectively 
managed and resolved, reflects a leader's lack ability to build strong relationships with followers that affect team morale and satisfaction (Newman \& Grigg, 2008).

Compromise conflict management is used to generate willingness between both parties to relinquish some control or power for the benefit of the organization (Bruk-Lee, 2007). The retail industry presents new conflicts in the form of diversified cultures and ethnic groups, poorly trained workforce, and a fluctuating economy that impacts retail sales (Reynolds, Howard, Cuthbertson, \& Hristov, 2007; Hinckley, 2009). Compromise conflict resolution strategies are necessary to turn a company around or to resolve issues about an employee's role (Goyal, Maruping, \& Robert, 2008; Hinckley, 2009). Transformational leaders have the charisma and interpersonal skills needed to incite followers to compromise on conflict resolution tactics (Bass \& Avolio, 2004; Bruk-Lee, 2007).

Laissez-Faire leadership is considered as an ineffective style when applied to conflict management situations (Bass \& Avolio, 2004; Bruk-Lee, 2007). Managers used an avoidance conflict management style to evade challenging issues within their retail work environment (Newman \& Grigg, 2008). Some researchers might view laissez-faire leaders to display leadership skills that attract an avoidance conflict management style. Today's retail leaders are expected to use effective leadership strategies to mediate and facilitate conflicts that impact the internal work environment (Newman \& Grigg, 2008). When retail organizations choose a conflict resolution strategy, such as compromise conflict management, leaders must make sure that the right strategies are chosen and beneficial to all vested parties (Goyal, Maruping, \& Robert, 2008). The present study addresses the following research questions:

- Do successful retail managers exhibit a leadership style that promotes collaborative work efforts?

- Does the advantageous leadership style correlate with a collaborative conflict management style?

- Does poor leadership correlate with ineffective conflict management styles?

\section{Methodology}

The instruments used for this study were MLQ and CMS; MLQ was used to test retail managers' leadership styles, and CMS was used to test their conflict management resolution style. Researcher obtained permission to use both instruments for the sole purpose of this research study. MLQ is one of the most validated and reliable instruments used to test managers' leadership styles (Bass \& Avoilo, 2004). The MLQ is a comprehensive survey that is composed of 45 -items, and uses a Likert-type scale to determine the transformational, transactional, and laissez-faire leadership styles (Bass \& Avolio, 2004). There are 12 leadership style scales: idealized influence (attributed), idealized influence (behavior), inspirational motivation, intellectual stimulation, individualized consideration; contingent reward, management-by-exception (active), managementby-exception (passive), laissez-faire leadership, extra effort, effectiveness, and satisfaction.

The CMS instrument provided information about an individual's approach to managing conflict. The survey data assisted individuals with an understanding of behaviors in conflicting situations. Conflicts that occur in interpersonal, group, and intergroup settings were addressed in the grid format, providing a five-fold conflict management profile. An effective tool to identify outcomes of conflict is the CMS (Teleometrics, 2007). Retail companies in the Louisville, Kentucky demographic area were randomly selected. Participants who participated in this study consisted of retail managers and employees in Louisville, Kentucky. Respondents were asked to assess the leadership styles (MLQ) and conflict management styles (CMS) of successful retail managers in their organization.

For this study purpose, results from the two instruments can be used to determine leadership styles and conflict management styles used among successful retail managers. Respondents volunteered and signed a consent form to participate in this research study. Data were collected and analyzed by the researcher and with the assistance of SPSS (17.0). Descriptive and a Pearson Correlation analysis were used to present the research findings.

\section{Data Collection}

The CMS and MLQ survey instruments were paper-and-pencil self-administered surveys that were mailed to participating organizations in Louisville, KY. Within each packet were instructions for the executive manager to distribute the sealed survey envelopes that were labeled manager and employee, to the participating managers and employees. The packets contained the researchers contact information, demographic questionnaire, instructions for completing and returning the surveys, and a stamped envelope with the researchers mailing address to return the completed surveys. Two follow-up phone calls were made to the participating retail establishments within two-week intervals: two weeks after acknowledgement of receiving the packets and a final call was made two weeks later.

\section{Results}

The profile of respondents provides an insight into the potential benefit of transformational leadership combined with compromise conflict management. There was a small paucity of respondents (32) used for this research compared to the targeted number of respondents (100), to indicate a $32 \%$ response rate. Only usable surveys were statistically analyzed, and surveys were deemed unusable from incompleteness or failure to mail back to the researcher. According to Creswell (2002), mailed surveys have a low-response rate, and it may have impacted the response rate of this research study. The sample population consisted of $56.3 \%$ male and $43.8 \%$ female, so the sample population was fairly balanced for this study in Table 1 . The most common age categories were 22 to 25 (21.9\%) and 31 to 40 (21.9\%), and only $9.4 \%$ of the respondents were over 50 years of age at the time of this study.

The results also indicated that respondents were most likely to have a high school diploma or GED (31.3\%) followed by some college (28.1\%). Respondents were not likely to have an advanced degree with only two people (6.3\%) having a master's degree; both were managers. Table 1 indicated that respondents were most likely to be Caucasian (46.9\%) followed by African American (43.8\%). Only two participants were Hispanic (6.3\%), none were Asian or Native American, and one person identified himself as other (3.1\%). The findings indicated $37.5 \%$ of the sample identified themselves as managers while $62.5 \%$ of the sample identified themselves as sales associates.

Table 2 provides the descriptive statistics for the three lead- 
ership sub-scales leadership within MLQ. The conflict management raw scores were converted to $\mathrm{T}$ scores as instructed in the CMS manual. The range of possible $\mathrm{T}$ scores and the median score for each of the five subscales are based on what was found in the current sample and what the normative sample for this instrument is scored. The results are presented in Table 3. The results indicate that on average, the managers were rated slightly above the median $\mathrm{T}$ score for collaboration (43.00), below the median $\mathrm{T}$ score for compromise (45.31), above the median $\mathrm{T}$ score for accommodation (56.25), above the median $\mathrm{T}$ score for authoritarian controlling (53.81), and above the median $\mathrm{T}$ score for avoidance (57.59). The minimums, maximums and the standard deviations indicated there was a relatively large amount of variability in the scores. The findings appear to be skewed due to the large standard deviations and outliers that are impacting the scores mean. The Pearson correlation results provided in Table $\mathbf{4}$ indicated that collaboration conflict management scores were negatively and statistically significantly correlated with transactional leadership scores, $r=$ $-0.368(31), p<0.05$, in higher transactional leadership scores are moderately associated with lower collaboration conflict management scores.

Table 1.

Respondents characteristics table.

\begin{tabular}{|c|c|c|}
\hline Gender & Frequency & Percent \\
\hline Male & 18 & 56.3 \\
\hline Female & 14 & 43.8 \\
\hline Age & Frequency & Percent \\
\hline $18-21$ & 6 & 18.8 \\
\hline $22-25$ & 7 & 21.9 \\
\hline $26-30$ & 4 & 12.5 \\
\hline $31-40$ & 7 & 21.9 \\
\hline $41-50$ & 5 & 15.6 \\
\hline $51-60$ & 2 & 6.3 \\
\hline 61 plus & 1 & 3.1 \\
\hline Education & Frequency & Percent \\
\hline Less than high school & 2 & 6.3 \\
\hline High school diploma (GE) & 10 & 31.3 \\
\hline Some college & 9 & 28.1 \\
\hline Associates degree & 4 & 12.5 \\
\hline Bachelor's degree & 5 & 15.6 \\
\hline Master's degree & 2 & 6.3 \\
\hline Doctoral degree & 0 & 0.0 \\
\hline Professional degree & 0 & 0.0 \\
\hline Race & Frequency & Percent \\
\hline Caucasian & 15 & 46.9 \\
\hline African American & 14 & 43.8 \\
\hline Hispanic & 2 & 6.3 \\
\hline Asian & 0 & 0.0 \\
\hline Native American & 0 & 0.0 \\
\hline Other & 1 & 3.1 \\
\hline Job title & Frequency & Percent \\
\hline Manager & 12 & 37.5 \\
\hline Sales associate & 20 & 62.5 \\
\hline
\end{tabular}

Table 2.

Means and standard deviations for the leadership subscale scores.

\begin{tabular}{lcccc}
\hline \multicolumn{1}{c}{ Source } & Minimum & Maximum & Mean & SD \\
\hline Transformational leadership & 1.10 & 4.00 & 3.02 & 0.74 \\
Transactional leadership & 1.13 & 4.00 & 2.83 & 0.70 \\
Laissez faire leadership & 0.00 & 4.00 & 1.38 & 1.34 \\
\hline
\end{tabular}

Table 3.

Means and standard deviations for the conflict management subscale T scores.

\begin{tabular}{lcccc}
\hline \multicolumn{1}{c}{ Source } & Minimum & Maximum & Mean & SD \\
\hline Collaboration & 27 & 75 & 43.00 & 10.85 \\
Compromise & 30 & 67 & 45.31 & 9.09 \\
Accommodation & 39 & 67 & 56.25 & 7.37 \\
Authoritarian controlling & 44 & 70 & 53.81 & 7.14 \\
Avoidance & 30 & 71 & 57.59 & 10.30 \\
\hline
\end{tabular}

Table 4.

Pearson correlation results: leadership and conflict management.

\begin{tabular}{lccc}
\hline \multicolumn{1}{c}{ Source } & Transformational & Transactional & Laissez faire \\
\hline Collaboration & -0.192 & $-0.368^{*}$ & $-0.591^{* *}$ \\
Compromise & -0.123 & -0.201 & -0.217 \\
$\begin{array}{l}\text { Accommodation } \\
\begin{array}{l}\text { Authoritarian } \\
\text { controlling }\end{array}\end{array}$ & -0.134 & -0.153 & 0.038 \\
Avoidance & 0.139 & 0.223 & 0.201 \\
${ }^{*} p<.05 .{ }^{* *} p<.01$. & -0.078 & 0.165 & $0.453^{* *}$ \\
\hline
\end{tabular}

\section{Discussion and Conclusion}

Effective leadership qualities are beneficial in today's complex and diverse retail organizations because today's retail organizations are facing conflicts that arise from personnel, customers, and competing retail entities (Assegid, 2009). Transformational leadership has proven to be an effective leadership style among retail managers and employees surveyed for this study. However, transformational leadership was not shown to correlate with effective conflict management styles among respondents, but a larger sample pool could yield more statistical sound findings that correlate with successful conflict management resolutions. There was a significant positive relationship of retail managers' laissez faire leadership style and avoidance conflict management style. The data from the Pearson correlation analysis revealed that the laissez-faire leadership style had a strong influence on employees for avoiding conflict.

Laissez-faire and avoidance conflict management appears to be the trend among retail managers, and this leadership and conflict management style combination can prove detrimental to retail organizations. Avoidance can create a culture that is resistant to change, and resistance to change can impede the decision-making tactics and strategic plans ineffective in a complex retail organizations (Graham, 2006). According to the research study correlational results, majority of the retail managers choose a laissez-faire style when resolving conflict inter- 
nal and external conflicts. However, retail human resource managers are seeking managers who provide guidance, encourage employees to take ownership of issues and solve problems, and to think critically before resolving solutions (McGrane, Wilson, \& Cammock, 2005).

When leaders fail to act proactively to resolve conflicts, it can create a work atmosphere that is reluctant to change and fosters internal conflicts (Hinckley, 2009). Based on the continuous research of leadership, transformational seems to be the most effective leadership style when resolving conflict. In the retail industry, leaders must equip themselves with skills and knowledge to manage conflict effectively (Bennett, 2009). The current findings suggest that most successful retail leaders exhibit transformational leadership traits, but they fail to incorporate those skills when attempting to manage conflicts. The current findings presented failed to fully support previous research findings, and it could be due to the small sample size; a larger sample size should be used to build on these research results.

The results can be applied in retailing industry by implementing training programs that inspire retail managers to develop and use transformational leadership skills when managing turnover or conflicts among co-workers. This approach can be used to improve the high turnover in the retail industry and conflict deriving from low-morale in this complex industry. Training programs that teach managers to be proactive can help to dispel a laissez-faire leadership style among retail managers. Academia can use the results by emphasizing the importance of proactively addressing issues rather than relying on avoidance techniques. Academia can implement group assignments and projects that force students to proactively resolve daily issues in the retail industry. Case studies can also be used in senior-level courses to promote effective leadership styles and successful conflict management styles.

Future studies can be used to explore why transformational leaders regress to an avoidance conflict management style when attempting to resolve conflicts. Another future recommendation is to examine male managers versus female managers and the differences of leadership styles when managing conflict. A larger sample size should be used to strengthen the research findings of this study. Future studies can also be used to examine the leadership and conflict management traits among specific age groups. For example, more and more young managers are entering the career field, and those individuals are expected to manage potential contingencies on a daily basis.

\section{REFERENCES}

Ackoff, R. (1999). Transformational leadership. Strategy \& Leadership, 27, 20-25. doi:10.1108/eb054626
Assegid, Y. (2009). What sets true leaders apart? Integral Leadership Review, 9, 1-11.

Banerji, P., \& Krishnan, V. R. (2000). Ethical preferences of transformational leaders: An empirical investigation. Leadership and Organization Development Journal, 21, 405-413. doi:10.1108/01437730010358161

Bass, B. M., \& Avolio, B. J. (2004). Multifactor leadership questionnaire: Manual and sampler set (3rd ed.). CA: Mind Garden, Inc.

Bennett, T. (2009). A study of the management leadership style preferred by it subordinates. Journal of Organizational Culture, Communication, and Conflict, 13, 1-25.

Bruk-Lee, V. (2007). Conflict management. Encyclopedia of Industrial and Organizational Psychology, 1, 94-99.

Creswell, J. W. (2005). Educational research: Planning, conducting, and evaluating quantitative and qualitative research. Upper Saddle River, NJ: Pearson.

Danley, J. (2006). Ethical behavior for today's workplace. College and University Educational Journal, 81, 53.

Eagly, A. H., Johannesen-Schmidt, M. C., \& Van Engen, M. L. (2003). Transformational, transactional, and laissez faire leadership styles: A meta-analysis comparing men and women. Psychological Bulletin, 129, 569-591. doi:10.1037/0033-2909.129.4.569

Graham, S. (2006). Diversity: Leaders not labels-A new plan for the 21st century. New York: Free Press.

Goyal, S., Maruping, L., \& Robert, L. (2008). Diversity and conflict in teams: A fault line model perspective. Academy of Management Proceedings, 6.

Hinckley, P. (2009). Making change work. American School Board Journal, 196, 27-28.

Kanchier, C. (2005). Dealing with difficult people. The Gazette, p. B6.

Katz, R. (2005). Motivating technical professionals today. Research Technology Management, 48, 19-27.

Korkmaz, M. (2007). The effects of leadership styles on organizational health. Educational Research Quarterly, 30, 22-53.

Latham, J., \& Vinyard, J. (2004). Baldrige user's guide: Organization diagnosis, design, and transformation. New York: Wiley.

McGrane, F., Wilson, J., \& Cammock, T. (2005). Leading employees in one-to-one dispute resolution. Leading \& Organization Development Journal, 26, 263-279. doi:10.1108/01437730510600643

Newman, J., \& Griggs, D. (2008). Productivity affected by the way teams handle conflict. The Vancouver Sun, F6.

Reynolds, J., Howard, E., Cuthbertson, C., \& Hristov, L. (2007). Perspectives on retail format innovation: Relating theory and practice. International Journal of Retail and Distribution Management, 35, 647-660. doi:10.1108/09590550710758630

Runde, C., \& Flanagan, T. (2008). Conflict competent leadership. Leader to Leader, 47, 46-51.

Sheard, A. G., \& Kakabadse, A. P. (2002). Key roles of the leadership landscape. Journal of Managerial Psychology, 17, 129. doi:10.1108/02683940210417058

Teleometrics, (2007). Leadership management. http://www.teleometrics.com

Tubbs, S. L., \& Schulz, E. (2006). Exploring a taxonomy of global leadership competencies and meta-competencies. Journal of American Academy of Business, Cambridge, 8, 29-34. 